\title{
Clinical value of serum albumin level in patients with non- small cell lung cancer and anaplastic lymphoma kinase (ALK) rearrangement
}

\author{
Xin Zhang, Puyuan Xing, Xuezhi Hao, Junling Li \\ Department of Medical Oncology, National Cancer Center/National Clinical Research Center for Cancer/Cancer Hospital, Chinese Academy of \\ Medical Science and Peking Union Medical College, Beijing, China \\ Contributions: (I) Conception and design: X Zhang, J Li; (II) Administrative support: J Li; (III) Provision of study materials or patients: All authors; \\ (IV) Collection and assembly of data: All authors. (V) Data analysis and interpretation: X Zhang; (VI) Manuscript writing: All authors; (VII) Final \\ approval of manuscript: All authors. \\ Correspondence to: Junling Li. Department of Medical Oncology, National Cancer Center/National Clinical Research Center for Cancer/ \\ Cancer Hospital, Chinese Academy of Medical Science and Peking Union Medical College, 17 Panjiayuan Nanli Street, Beijing 100021, China. \\ Email: lijunling@cicams.ac.cn.
}

Background: There are few data on the clinical value of serum albumin (Alb) level as a prognostic indicator in advanced non-small cell lung cancer (NSCLC) patients with positive anaplastic lymphoma kinase (ALK) rearrangement. Thus, we retrospectively analyzed the clinicopathological features of advanced, ALKpositive NSCLC patients diagnosed and treated at our institution to investigate the effects of pretreatment serum Alb on outcome in this patient setting.

Methods: We selected 261 consecutive patients with newly diagnosed pathologically or cytologically confirmed NSCLC harboring ALK rearrangement between May 2016 and February 2018. The targetindependent and dependent variables were Serum albumin level measured in patients before anticancer treatment and progression-free survival (PFS). Pre-treatment serum Alb levels and demographic, clinical, and histological characteristics, as well as outcome variables were recorded and analyzed. Serum albumin level was estimated before treatment and at every visit. The pretreatment and the lowest serum albumin level during treatment were recorded.

Results: The mean pretreatment Alb level was $42.185 \mathrm{~g} / \mathrm{L}$. Before the treatment initiation, low Alb level $(<40 \mathrm{~g} / \mathrm{L})$ was measured in $74(28.4 \%)$ patients and normal Alb $(\geq 40 \mathrm{~g} / \mathrm{L})$ was measured in $187(71.6 \%)$ participants. Low pretreatment Alb $(<40 \mathrm{~g} / \mathrm{L})$ was more highly prevalent in those with pleural effusion $(\mathrm{P}=0.013)$. Pretreatment hypoalbuminemia was significantly associated with shorter progression-free survival (PFS) [8.0 months, 95\% confidence interval (CI): 4.56-11.44 vs. 12.0 months, 95\% CI: 9.85-14.15; $\mathrm{P}=0.046]$. Crizotinib-treated participants had a significantly prolonged PFS compared to those treated with chemotherapy, regardless of Alb level [normal Alb level: 19.0 (95\% CI: 12.72-25.28) vs. 8.0 (95\% CI: 6.22-9.78), $\mathrm{P}<0.001$; low Alb level: 12.0 months (95\% CI: 10.13-13.87) vs. 6.0 months (95\% CI: 2.95-9.05), $\mathrm{P}=0.006]$. Multivariate analyses indicated that poor Eastern Cooperative Oncology Group performance status (ECOG PS) [hazard ratio $(\mathrm{HR})=1.66 ; 95 \% \mathrm{CI}: 1.16-2.38 ; \mathrm{P}=0.005$ ] and presence of pleural effusion $(\mathrm{HR}=2.43$; 95\% CI: $1.55-3.82 ; \mathrm{P}<0.001)$ were significantly independent predictive factors for PFS in ALKpositive NSCLC.

Conclusions: Pretreatment hypoalbuminemia is associated with poor outcome of NSCLC patients harboring ALK rearrangement. However, the role of the pretreatment serum Alb level as predictive biomarker requires further investigation.

Keywords: Anaplastic lymphoma kinase (ALK); non-small cell lung cancer (NSCLC); serum albumin level; predictive factor; prognostic factor 
Submitted Oct 14, 2021. Accepted for publication Dec 22, 2021.

doi: 10.21037/apm-21-3379

View this article at: https://dx.doi.org/10.21037/apm-21-3379

\section{Introduction}

According to US cancer statistics, $1,762,450$ new cancer cases are diagnosed each year, of which 228,150 are lung cancers (1). Lung cancer is the most common cause of malignancy-related mortality worldwide, and responsible for 142,670 deaths annually (1). Non-small cell lung cancer (NSCLC) is the dominant histopathological type of lung cancer, which comprises $85 \%$ of all cases. Despite progress in diagnostic techniques and treatment, NSCLC still shows a poor 5 -year survival rate (2). Several factors have been identified as predictors for patient survival, including gender, performance status (PS), disease extent, age, lactate dehydrogenase, CEA value, and neutrophil counts in NSCLC (3-8). However, their predictive power is reduced and barely transferrable to clinical use. Thus, it is important to recognize specific, sensitive, and easilyobtained biomarkers for NSCLC prognosis.

Anaplastic lymphoma kinase (ALK) gene rearrangements were firstly reported in 2007, and significant advances have been witnessed in their drug development for NSCLC $(9,10)$. ALK rearrangement is fusion results from a small inversion within chromosome $2 \mathrm{p}$, which leads to expression of a chimeric tyrosine kinase, in which the $\mathrm{N}$-terminal half of echinoderm microtubule-associated protein-like 4 (EML4) is fused to the intracellular kinase domain of anaplastic lymphoma kinase (10). Present in $4-5 \%$ of NSCLC, ALK defines a molecular subset of NSCLC with distinct clinical characteristics, including never/ light smoking history, adenocarcinoma histology, and younger age (11). The ALK-positive cancers are highly sensitive to small-molecule ALK kinase inhibitors, such as crizotinib, ceritinib, alectinib, brigatinib, and lorlatinib (12-23). The discovery of ALK gene rearrangements and the development of anti-ALK agents have significantly changed the paradigm of treatment for NSCLC.

Albumin (Alb) is a plasma protein produced by the liver and is a commonly used biomarker for malnutrition, inflammation, and hepatic dysfunction. Malnutrition and inflammation are often seen in cancer patients. The progression of tumors, including lung cancer, is closely associated with cancer-related inflammation and malnutrition due to their suppression of Alb synthesis (24). Serum Alb level, alone or as a component of scoring systems [e.g., prognostic nutritional index (PNI), Glasgow Prognostic Score (GPS)], has been assessed in multiple malignancies as a prognostic marker (24-28). There are a few studies have investigated the impact of serum Alb level on disease prognosis in NSCLC patients harboring ALK rearrangement. However, there still are many questions unsolved. Here, we conducted a retrospective analysis to determine whether serum Alb level is related to prognosis in NSCLC patients harboring positive ALK, and to clarify the relationships between serum Alb level and clinicoradiographic characteristics of NSCLC patients with ALK rearrangement. We also analyze the difference for hypoalbuminemia as a prognostic factor between different treatment (Crizotinib vs chemotherapy) for advanced NSCLC patients with ALK rearrangement. We present the following article in accordance with the REMARK reporting checklist (available at https://dx.doi.org/10.21037/apm-21-3379).

\section{Methods}

In this retrospective study, we analyzed the medical records of 261 consecutive patients with newly diagnosed, pathologically or cytologically confirmed NSCLC harboring ALK rearrangement between May 2016 and February 2018 at Cancer Hospital, Chinese Academy of Medical Sciences \& Peking Union Medical College.

Inclusion criteria were as follows: (I) patients with either histologically or cytologically confirmed diagnosis of ALK-positive advanced NSCLC; (II) sociodemographic, clinicopathological characteristics, and complete follow-up information of all patients were available; (III) patients were not receiving any anticancer therapies at the time of initial diagnosis; (IV) there was no concurrent malignancy or a history of a second primary malignancy. Patients with small cell lung cancer or staged with not advanced NSCLC or incomplete baseline information were excluded.

Clinical characteristics such as age, gender, Eastern Cooperative Oncology Group performance status (ECOG PS), smoking status, histological classification, disease stage, and ALK status were investigated. The PS was recorded according to the ECOG PS scores. Tumor stage was determined according to the seventh edition of the tumor-node-metastasis (TNM) staging system by the 
Table 1 Patient characteristics

\begin{tabular}{|c|c|}
\hline Characteristics & Value \\
\hline Age, median [range], years & 51 [20-83] \\
\hline \multicolumn{2}{|l|}{ Gender, n (\%) } \\
\hline Male & $128(49.0)$ \\
\hline Female & $133(51.0)$ \\
\hline \multicolumn{2}{|l|}{ Histology type, n (\%) } \\
\hline Adenocarcinoma & $256(98.1)$ \\
\hline Adenosquamous carcinoma & $1(0.4)$ \\
\hline Other & $4(1.5)$ \\
\hline \multicolumn{2}{|c|}{ Presence of pleural effusion, n (\%) } \\
\hline Yes & $52(19.9)$ \\
\hline No & $209(80.1)$ \\
\hline \multicolumn{2}{|l|}{ Disease stage, n (\%) } \\
\hline IIIB & $18(6.9)$ \\
\hline IV & $243(93.1)$ \\
\hline \multicolumn{2}{|l|}{ ECOG status, n (\%) } \\
\hline 0 & $158(60.5)$ \\
\hline 1 & $90(34.5)$ \\
\hline$\geq 2$ & $13(5.0)$ \\
\hline \multicolumn{2}{|l|}{ First-line therapy, n (\%) } \\
\hline Chemotherapy & $99(37.9)$ \\
\hline Crizotinib & $154(59.0)$ \\
\hline Other & $8(3.1)$ \\
\hline
\end{tabular}

ECOG, Eastern Cooperative Oncology Group.

American Joint Committee on Cancer. The ALK status was determined by immunohistochemistry (IHC), fluorescence in situ hybridization (FISH), polymerase chain reaction (PCR), or next generation sequencing (NGS). Response results, progression-free survival (PFS), and overall survival (OS) were investigated to evaluate outcomes. Tumor responses were assessed according to the response evaluation criteria in solid tumors (RECIST) v1.1 by computed tomography (CT) scan or magnetic resonance imaging (MRI) every 6-8 weeks. The PFS was defined as the time from the date of treatment to the date of disease progression or death.

Alb were tested on a beckman coulter AU680 automatic biochemical analyzer using the manufacturer's reagents. Quality control follows good laboratory practice (GLP).
Serum Alb level was estimated before treatment and at every visit. The pretreatment and the lowest serum Alb level during treatment were recorded. The cut-off value for Alb was chosen according to the normal range in serum biochemistry testing, which was $4 \mathrm{~g} / \mathrm{dL}$ corresponding to the normal limits given by the local laboratory at our institute. Participants with serum Alb levels under $4 \mathrm{~g} / \mathrm{dL}$ were considered to be hypoalbuminemia. All procedures performed in this study involving human participants were in accordance with the Declaration of Helsinki (as revised in 2013). The study was approved by the Ethics Committee of National Cancer Center/Cancer Hospital, Chinese Academy of Medical Science and Peking Union Medical College (No. 18-102/1680). Individual consent for this retrospective analysis was waived.

\section{Statistical analysis}

The categorical variables were analyzed by chi-square and Fisher's exact tests, and continuous variables were analyzed by Student's t test. Kaplan-Meier method was used to estimate the OS and PFS in all participants and in subgroups, and differences between each group were calculated using the log-rank test. Multivariate analysis was performed using Cox proportional hazard regression models. A P value $<0.05$ was taken to indicate statistical significance. Analyses were carried out using SPSS version 22.0 (IBM Corp., Chicago, IL, USA).

\section{Results}

Baseline population characteristics are presented in Table 1 . The median age was 51 years (range, 20-83 years) with $51.0 \%$ being female. The study population included a vast majority of adenocarcinoma (98.1\%), stage IV disease (93.1\%) with $14.2 \%$ of patients having pleural effusion. Most participants showed a well-preserved physical condition at the time of evaluation, with 248 (95.0\%) out of 261 participants having a PS of 0 or 1 (Table 1). A total of 99 participants received chemotherapy as first-line treatment, 154 received crizotinib, whereas 8 participants received other targeted treatment. Each patient's treatment was chosen by his/her doctor in charge. No difference was detected for the proportion of hypoalbuminemia among treatment groups $(\mathrm{P}=0.810)$.

The mean pretreatment Alb level was $42.185 \mathrm{~g} / \mathrm{L}$. Table 2 shows that low Alb was $(<40 \mathrm{~g} / \mathrm{L})$ measured in $74(28.4 \%)$ participants and normal albumin $(\geq 40 \mathrm{~g} / \mathrm{L})$ was measured 
Table 2 Participant characteristics divided according to serum Alb $<40$ and $\geq 40 \mathrm{~g} / \mathrm{L}$

\begin{tabular}{|c|c|c|c|}
\hline \multirow[t]{2}{*}{ Characteristics } & \multicolumn{2}{|c|}{$\begin{array}{l}\text { Pretreatment serum } \\
\text { albumin level }\end{array}$} & \multirow[t]{2}{*}{$P$ value } \\
\hline & $<40 \mathrm{~g} / \mathrm{L}$ & $\geq 40 \mathrm{~g} / \mathrm{L}$ & \\
\hline Age & & & 0.077 \\
\hline$<60$ years & 50 & 146 & \\
\hline$\geq 60$ years & 24 & 41 & \\
\hline Gender & & & 0.238 \\
\hline Male & 32 & 96 & \\
\hline Female & 42 & 91 & \\
\hline ECOG score & & & 0.833 \\
\hline 0 & 42 & 116 & \\
\hline 1 & 28 & 62 & \\
\hline 2 & 3 & 7 & \\
\hline 3 & 1 & 2 & \\
\hline Histology type & & & 1.000 \\
\hline Adenocarcinoma & 73 & 183 & \\
\hline Adenosquamous carcinoma & 0 & 1 & \\
\hline Other & 1 & 3 & \\
\hline Presence of pleural effusion & & & 0.013 \\
\hline Yes & 22 & 30 & \\
\hline No & 52 & 157 & \\
\hline Disease stage & & & 0.550 \\
\hline IIIB & 4 & 14 & \\
\hline IV & 70 & 173 & \\
\hline First-line therapy & & & 0.810 \\
\hline Chemotherapy & 27 & 72 & \\
\hline Crizotinib & 44 & 110 & \\
\hline Other & 3 & 5 & \\
\hline
\end{tabular}

ECOG, Eastern Cooperative Oncology Group; Alb, albumin.

in $187(71.6 \%)$ before the treatment initiation. Participants with pretreatment albumin $<40 \mathrm{~g} / \mathrm{L}$ had a higher prevalence of pleural effusion $(\mathrm{P}=0.013)$, and older participants ( $\geq 60$ years) tended to have low-level Alb $(\mathrm{P}=0.077)$.

\section{Clinical outcome}

At data cut-off (June 2020), a total of 201 documented PFS

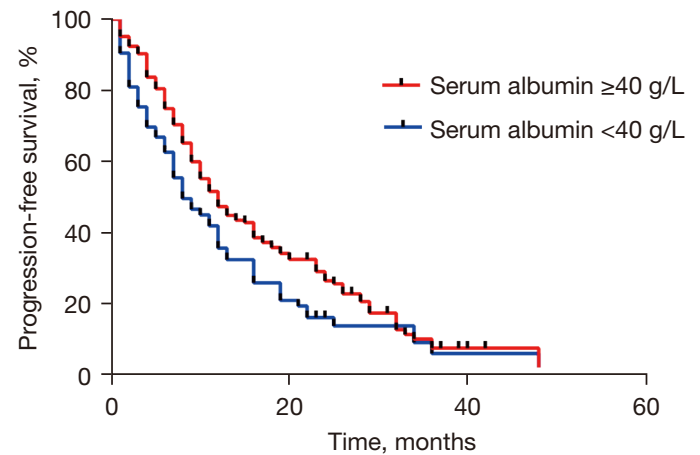

Figure 1 Progression-free survival (PFS) for the all population.

events were observed (median follow-up, 16.1 months). The median PFS in participants with pre-treatment hypoalbuminemia was significantly shorter than that in those with a normal pre-treatment serum Alb level [8.0 months (95\% CI: 4.56-11.44) vs. 12.0 months (95\% CI: 9.85-14.15), $\mathrm{P}=0.046$; Figure 1]. However, no difference was seen when stratified by treatment [crizotinib-treated patients (hypoalbuminemia vs. normal serum Alb): 12.0 months (95\% CI: 10.13-13.87) vs. 19.0 months (95\% CI: $12.72-25.28)$, $\mathrm{P}=0.072$, Figure $2 A$; chemotherapy: 6.0 months (95\% CI: 2.95-9.05) months vs. 8.0 (95\% CI: 6.22-9.78), $\mathrm{P}=0.191$, Figure 2B]. In addition, crizotinib yielded better PFS than chemotherapy regardless of pre-treatment serum Alb status, the $\mathrm{P}$ value was 0.006 and less than 0.001 for participants with pre-treatment hypoalbuminemia and normal serum Alb level, respectively (Figure 2C,2D). The Kaplan-Meier curves of PFS stratified by pretreatment Alb level and treatment are respectively shown in Figure 2. Response rate showed a similar trend when stratified by treatment and pretreatment serum Alb status (Figure 3).

Baseline clinical parameters were assessed together with serum Alb levels in univariate and multivariate analysis. In univariate analysis, older age, poor ECOG PS, and presence of pleural effusion were identified as adverse prognostic factors (Table 3). The multivariate Cox proportional hazards model revealed that ECOG PS (HR $=1.66$; 95\% CI: $1.16-$ 2.38; $\mathrm{P}=0.005)$ and presence of pleural effusion ( $\mathrm{HR}=2.43$; 95\% CI: $1.55-3.82 ; \mathrm{P}<0.001)$ were significantly independent predictive factors for PFS in ALK-positive NSCLC (Table 3).

\section{Discussion}

In this study, we examined the predictive value of pretreatment Alb status in a retrospective cohort of 261 locally advanced or metastatic NSCLC patients with 

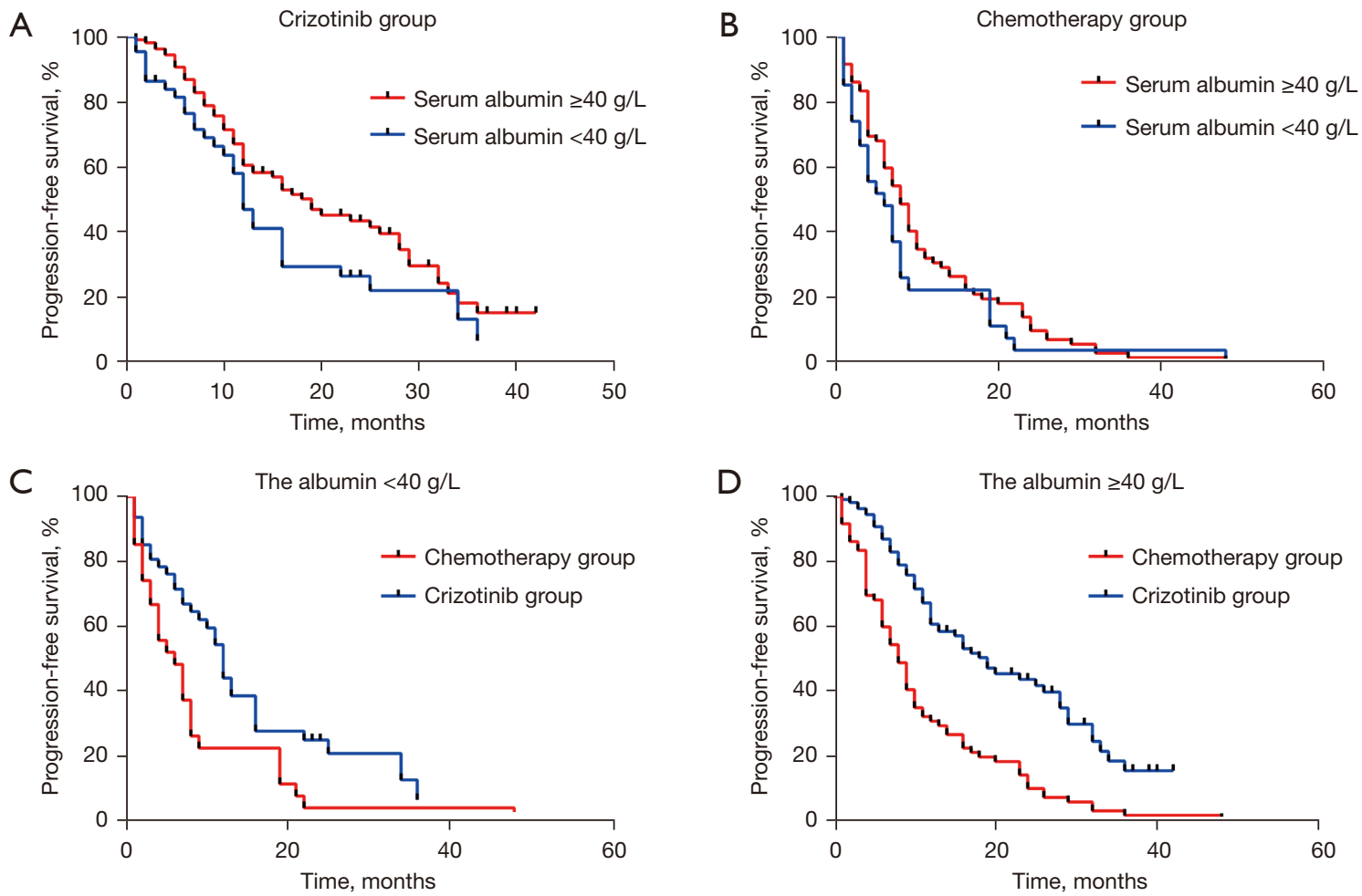

Figure 2 Progression-free survival (PFS) for crizotinib group (A), chemotherapy group (B), the albumin $<40 \mathrm{~g} / \mathrm{L}$ (C) and the albumin $\geq 40 \mathrm{~g} / \mathrm{L}(\mathrm{D})$.
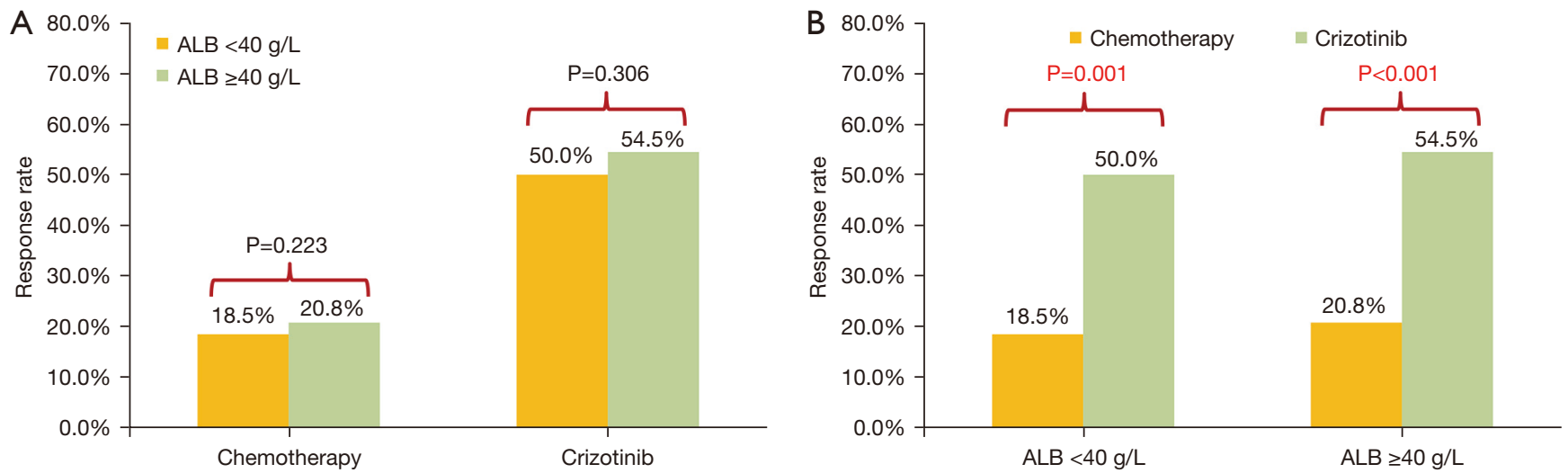

Figure 3 Response rate stratified by treatment and pretreatment serum albumin status.

positive ALK. To the best of our knowledge, the current study is the first to describe the correlation between pretreatment Alb status and clinical outcome in ALKpositive NSCLC patients. Participants with normal Alb level ( $\geq 40 \mathrm{~g} / \mathrm{L})$ had better PFS, and ECOG PS and presence of pleural effusion were independent prognostic factors in multivariable models.
Produced by the liver, Alb helps to maintain intravascular pressure and balance blood $\mathrm{pH}$, as well as showing visceral protein function which represents the degree of malnutrition (29,30). Decreased serum Alb level is commonly seen in cancer patients due to cancer-related inflammation, cachexia, and malnutrition (cancer-related or treatment-related). Emerging data has demonstrated 
Table 3 Univariate and multivariate Cox proportional hazards regression analyses

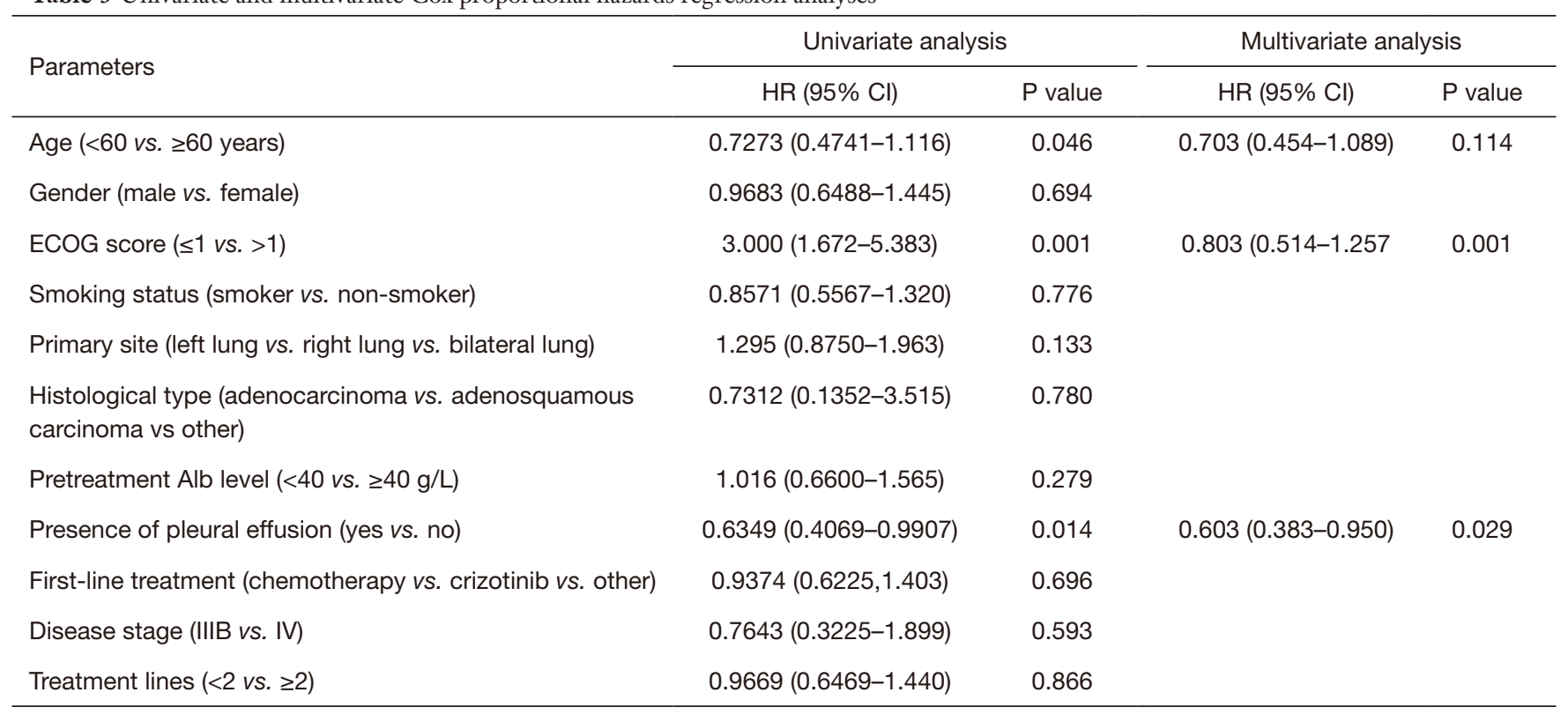

$\mathrm{HR}$, hazard ratio; $\mathrm{Cl}$, confidence interval; Alb, albumin.

a correlation between hypoalbuminemia and survival outcome in cancer patients, including those with lung cancer (25-28,31). Espinosa et al. reported that Alb level was predictive for survival in non-operable NSCLC which consisted of a heterogeneous population (31). For early-stage disease, pre-operative hypoalbuminemia was found to be significantly correlated with larger tumor size and visceral pleural invasion, and hypoalbuminemia has been reported as a negative prognostic factor for tumor recurrence and survival in patients with resected NSCLC $(32,33)$. In other cohort studies, investigators have reported relationships between Alb-contained models such as albumin-to-alkaline phosphatase ratio (AAPR), PNI, or GPS and the prognosis of lung cancer (34-38). Significant unfavorable OS and disease-free survival (DFS) was seen in resected NSCLC patients with low AAPR (36). High pretreatment albumin and neutrophil combined prognostic grade (ANPG), high fibrinogen and serum Alb levels (FA score), and low PNI has been reported as a negative prognostic factor for survival $(35,36,39,40)$. The GPS is calculated with C-reactive protein and Alb values, and high GPS predicts poor prognosis for operable-stage lung cancer patients (38). For patients with NSCLC harboring driver mutation, Fiala et al. reported that hypoalbuminemia was the strongest factor predicting OS among those treated with erlotinib, even stronger than epidermal growth factor receptor
(EGFR) mutation (41). These findings suggest that serum Alb is an objective, simple, and effective marker that predicts survival outcomes even in the targeted therapy era.

Since its discovery, it has been well-established that ALK rearrangements predict favorable response to the treatment with ALK inhibitors in patients with advanced-stage NSCLC. With respect to Alb level, most previous studies were performed on patients treated with chemotherapy; in the present study, we focused on the impact of pretreatment serum Alb in a large cohort of patients with ALK-positive NSCLC. In this study, hypoalbuminemia was more common in participants with pleural effusion $(\mathrm{P}=0.013)$ and those older than 60 years $(\mathrm{P}=0.077)$, while clinical characteristics such as gender, histology, and disease stage did not affect the prevalence of hypoalbuminemia. We observed significantly shorter PFS for patients with hypoalbuminemia compared to those with normal-level serum Alb (8.0 vs. 12.0 months, $\mathrm{P}=0.046)$. A previous study demonstrated that Alb level identifies a group of NSCLC patients with hypoalbuminemia who are more likely to respond poorly to chemotherapy, which may be explained by the fact that malnourished patients tolerate chemotherapy poorly (31). In contrast to previous studies, despite a numerical difference, the difference was not statistically significant in chemotherapy-treated patients, the median PFS was 8.0 and 6.0 months according to pretreatment serum Alb level $(\mathrm{P}=0.191)$. A possible explanation 
was the limited sample size, only 27 chemotherapytreated patients with hypoalbuminemia were included in this analysis. Additionally, the chemotherapy regimen was pemetrexed plus cisplatin, which had better safety profile and less drug-related discontinuation than other regimens (42). For crizotinib-treated patients, pre-treatment hypoalbuminemia seemed to be associated with shorter PFS (12.0 vs. 19.0 months) with a borderline $\mathrm{P}$ value of 0.072 , suggesting relatively lower efficacy of ALK inhibitors in this population. Moreover, crizotinib yield better PFS benefit when compared with chemotherapy regardless of Alb status, indicating that crizotinib is still a preferable option for in ALK-positive patients with hypoalbuminemia.

The multivariate Cox proportional hazards model confirmed that poor ECOG PS and presence of pleural effusion were independently associated with shorter survival. Previous studies have demonstrated that Alb level can predict the prognosis of NSCLC patients (31-33). However, the prognostic value of Alb level was inconsistent in this study. We speculated that this difference may be attributed to the different populations enrolled in previous studies which mostly consisted of early-stage patients $(32,33)$. Moreover, the level of Alb is related to many factors, such as inflammation, hepatic insufficiency, and changes in the volume of body fluids.

This research was limited by the retrospective singlecenter cohort and small sample size. Since other ALK inhibitors (ceritinib, alectinib) were approved in 2018 in China, we only analyzed data from crizotinib-treated patients, and failed to collect treatment information after progression on first-line treatment. In addition, the Alb levels were influenced by many factors including disease stage, inflammation, hepatic insufficiency, and changes in the volume of body fluids. Future studies should take these factors into account.

In conclusion, the results of this retrospective study indicate that pretreatment hypoalbuminemia is associated with poor outcome of NSCLC patients harboring ALK rearrangement. Crizotinib provided a better option than chemotherapy in patients with low pretreatment Alb level. However, Alb level alone seems to be insufficient to predict the survival in ALK-positive NSCLC patients, better prognostic markers integrating Alb levels and other factors need to be investigated in future studies.

\section{Acknowledgments}

Funding: None.

\section{Footnote}

Reporting Checklist: The authors have completed the REMARK reporting checklist. Available at https://dx.doi. org/10.21037/apm-21-3379

Data Sharing Statement: Available at https://dx.doi. org/10.21037/apm-21-3379

Conflicts of Interest: All authors have completed the ICMJE uniform disclosure form (available at https://dx.doi. org/10.21037/apm-21-3379). The authors have no conflicts of interest to declare.

Ethical Statement: The authors are accountable for all aspects of the work in ensuring that questions related to the accuracy or integrity of any part of the work are appropriately investigated and resolved. All procedures performed in this study involving human participants were in accordance with the Declaration of Helsinki (as revised in 2013). The study was approved by the Ethics Committee of National Cancer Center/Cancer Hospital, Chinese Academy of Medical Science and Peking Union Medical College (No. 18-102/1680). Individual consent for this retrospective analysis was waived.

Open Access Statement: This is an Open Access article distributed in accordance with the Creative Commons Attribution-NonCommercial-NoDerivs 4.0 International License (CC BY-NC-ND 4.0), which permits the noncommercial replication and distribution of the article with the strict proviso that no changes or edits are made and the original work is properly cited (including links to both the formal publication through the relevant DOI and the license). See: https://creativecommons.org/licenses/by-nc-nd/4.0/.

\section{References}

1. Siegel RL, Miller KD, Jemal A. Cancer statistics, 2019. CA Cancer J Clin 2019;69:7-34.

2. Akamatsu H, Mori K, Naito T, et al. Progression-free survival at 2 years is a reliable surrogate marker for the 5 -year survival rate in patients with locally advanced nonsmall cell lung cancer treated with chemoradiotherapy. BMC Cancer 2014;14:18.

3. Yao Y, Gu X, Zhu J, et al. Hormone replacement therapy in females can decrease the risk of lung cancer: a metaanalysis. PLoS One 2013;8:e71236. 
4. Yao Y, Yuan D, Liu H, et al. Pretreatment neutrophil to lymphocyte ratio is associated with response to therapy and prognosis of advanced non-small cell lung cancer patients treated with first-line platinum-based chemotherapy. Cancer Immunol Immunother 2013;62:471-9.

5. Fizazi K, Cojean I, Pignon JP, et al. Normal serum neuron specific enolase (NSE) value after the first cycle of chemotherapy: an early predictor of complete response and survival in patients with small cell lung carcinoma. Cancer 1998;82:1049-55.

6. Paesmans M, Sculier JP, Lecomte J, et al. Prognostic factors for patients with small cell lung carcinoma: analysis of a series of 763 patients included in 4 consecutive prospective trials with a minimum follow-up of 5 years. Cancer 2000;89:523-33.

7. Roxburgh CS, McMillan DC. Role of systemic inflammatory response in predicting survival in patients with primary operable cancer. Future Oncol 2010;6:149-63.

8. Inomata $M$, Hayashi $\mathrm{R}$, Tokui $\mathrm{K}$, et al. Lactate dehydrogenase and body mass index are prognostic factors in patients with recurrent small cell lung cancer receiving amrubicin. Tumori 2016;102:606-9.

9. Soda M, Choi YL, Enomoto M, et al. Identification of the transforming EML4-ALK fusion gene in non-small-cell lung cancer. Nature 2007;448:561-6.

10. Rikova K, Guo A, Zeng Q, et al. Global survey of phosphotyrosine signaling identifies oncogenic kinases in lung cancer. Cell 2007;131:1190-203.

11. Vavalà T, Mariniello A, Novello S. Anaplastic lymphoma kinase tyrosine kinase inhibitors in non-small cell lung cancer. Transl Cancer Res 2019;8:S48-54.

12. Solomon BJ, Mok T, Kim DW, et al. First-line crizotinib versus chemotherapy in ALK-positive lung cancer. N Engl J Med 2014;371:2167-77.

13. Shaw AT, Kim DW, Nakagawa K, et al. Crizotinib versus chemotherapy in advanced ALK-positive lung cancer. $\mathrm{N}$ Engl J Med 2013;368:2385-94.

14. Kim DW, Mehra R, Tan DSW, et al. Activity and safety of ceritinib in patients with ALK-rearranged non-smallcell lung cancer (ASCEND-1): updated results from the multicentre, open-label, phase 1 trial. Lancet Oncol 2016;17:452-63.

15. Gadgeel SM, Gandhi L, Riely GJ, et al. Safety and activity of alectinib against systemic disease and brain metastases in patients with crizotinib-resistant ALK-rearranged non-small-cell lung cancer (AF-002JG): results from the dose-finding portion of a phase 1/2 study. Lancet Oncol 2014;15:1119-28
16. Ou SH, Ahn JS, De Petris L, et al. Alectinib in Crizotinib-Refractory ALK-Rearranged Non-SmallCell Lung Cancer: A Phase II Global Study. J Clin Oncol 2016;34:661-8.

17. Shaw AT, Kim TM, Crinò L, et al. Ceritinib versus chemotherapy in patients with ALK-rearranged nonsmall-cell lung cancer previously given chemotherapy and crizotinib (ASCEND-5): a randomised, controlled, openlabel, phase 3 trial. Lancet Oncol 2017;18:874-86.

18. Soria JC, Tan DSW, Chiari R, et al. First-line ceritinib versus platinum-based chemotherapy in advanced ALKrearranged non-small-cell lung cancer (ASCEND-4): a randomised, open-label, phase 3 study. Lancet 2017;389:917-29.

19. Hida T, Nokihara H, Kondo M, et al. Alectinib versus crizotinib in patients with ALK-positive non-small-cell lung cancer (J-ALEX): an open-label, randomised phase 3 trial. Lancet 2017;390:29-39.

20. Peters S, Camidge DR, Shaw AT, et al. Alectinib versus Crizotinib in Untreated ALK-Positive Non-Small-Cell Lung Cancer. N Engl J Med 2017;377:829-38.

21. Kim DW, Tiseo M, Ahn MJ, et al. Brigatinib in Patients With Crizotinib-Refractory Anaplastic Lymphoma KinasePositive Non-Small-Cell Lung Cancer: A Randomized, Multicenter Phase II Trial. J Clin Oncol 2017;35:2490-8.

22. Gettinger SN, Bazhenova LA, Langer CJ, et al. Activity and safety of brigatinib in ALK-rearranged non-small-cell lung cancer and other malignancies: a single-arm, openlabel, phase 1/2 trial. Lancet Oncol 2016;17:1683-96.

23. Shaw AT, Felip E, Bauer TM, et al. Lorlatinib in nonsmall-cell lung cancer with ALK or ROS1 rearrangement: an international, multicentre, open-label, single-arm firstin-man phase 1 trial. Lancet Oncol 2017;18:1590-9.

24. Alifano M, Mansuet-Lupo A, Lococo F, et al. Systemic inflammation, nutritional status and tumor immune microenvironment determine outcome of resected nonsmall cell lung cancer. PLoS One 2014;9:e106914.

25. Cengiz O, Kocer B, Sürmeli S, et al. Are pretreatment serum albumin and cholesterol levels prognostic tools in patients with colorectal carcinoma? Med Sci Monit 2006;12:CR240-7.

26. Boonpipattanapong T, Chewatanakornkul S. Preoperative carcinoembryonic antigen and albumin in predicting survival in patients with colon and rectal carcinomas. J Clin Gastroenterol 2006;40:592-5.

27. Oñate-Ocaña LF, Aiello-Crocifoglio V, Gallardo-Rincón $\mathrm{D}$, et al. Serum albumin as a significant prognostic factor for patients with gastric carcinoma. Ann Surg Oncol 
2007;14:381-9.

28. Lis CG, Grutsch JF, Vashi PG, et al. Is serum albumin an independent predictor of survival in patients with breast cancer? JPEN J Parenter Enteral Nutr 2003;27:10-5.

29. Laky B, Janda M, Bauer J, et al. Malnutrition among gynaecological cancer patients. Eur J Clin Nutr 2007;61:642-6.

30. Fuhrman MP, Charney P, Mueller CM. Hepatic proteins and nutrition assessment. J Am Diet Assoc 2004;104:1258-64.

31. Espinosa E, Feliu J, Zamora P, et al. Serum albumin and other prognostic factors related to response and survival in patients with advanced non-small cell lung cancer. Lung Cancer 1995;12:67-76.

32. Jin Y, Zhao L, Peng F. Prognostic impact of serum albumin levels on the recurrence of stage I non-small cell lung cancer. Clinics (Sao Paulo) 2013;68:686-93.

33. Miura K, Hamanaka K, Koizumi T, et al. Clinical significance of preoperative serum albumin level for prognosis in surgically resected patients with nonsmall cell lung cancer: Comparative study of normal lung, emphysema, and pulmonary fibrosis. Lung Cancer 2017;111:88-95.

34. Abu-Talib M, Brown LR. Albumin-to-alkaline phosphatase ratio as a novel prognostic indicator for patients undergoing minimally invasive lung cancer surgery: Propensity score matching analysis using a prospective database. Int J Surg 2019;69:152.

35. Shoji F, Morodomi Y, Akamine T, et al. Predictive impact for postoperative recurrence using the preoperative prognostic nutritional index in pathological stage I nonsmall cell lung cancer. Lung Cancer 2016;98:15-21.

Cite this article as: Zhang X, Xing P, Hao X, Li J. Clinical value of serum albumin level in patients with non-small cell lung cancer and anaplastic lymphoma kinase (ALK) rearrangement. Ann Palliat Med 2021;10(12):12403-12411. doi: 10.21037/apm21-3379
36. Shimizu K, Okita R, Saisho S, et al. Preoperative neutrophil/lymphocyte ratio and prognostic nutritional index predict survival in patients with non-small cell lung cancer. World J Surg Oncol 2015;13:291.

37. Tomita M, Ayabe T, Chosa E, et al. Prognostic significance of pre- and postoperative glasgow prognostic score for patients with non-small cell lung cancer. Anticancer Res 2014;34:3137-40.

38. Yotsukura M, Ohtsuka T, Kaseda K, et al. Value of the Glasgow Prognostic Score as a Prognostic Factor in Resectable Non-Small Cell Lung Cancer. J Thorac Oncol 2016;11:1311-8.

39. Chen P, Wang C, Cheng B, et al. Plasma fibrinogen and serum albumin levels (FA score) act as a promising prognostic indicator in non-small cell lung cancer. Onco Targets Ther 2017;10:3107-18.

40. Sun H, Hu P, Shen H, et al. Albumin and Neutrophil Combined Prognostic Grade as a New Prognostic Factor in Non-Small Cell Lung Cancer: Results from a Large Consecutive Cohort. PLoS One 2015;10:e0144663.

41. Fiala O, Pesek M, Finek J, et al. Serum albumin is a strong predictor of survival in patients with advanced-stage nonsmall cell lung cancer treated with erlotinib. Neoplasma 2016;63:471-6.

42. Scagliotti GV, Parikh P, von Pawel J, et al. Phase III study comparing cisplatin plus gemcitabine with cisplatin plus pemetrexed in chemotherapy-naive patients with advanced-stage non-small-cell lung cancer. J Clin Oncol 2008;26:3543-51.

(English Language Editor: A. Kassem) 